Volume 8, No.6, November - December 2019

International Journal of Advanced Trends in Computer Science and Engineering

Available Online at http://www.warse.org/IJATCSE/static/pdf/file/ijatcse144862019.pdf

https://doi.org/10.30534/ijatcse/2019/144862019

\title{
A New Approach for Solving Rough Interval MCDM Problems Based on BWM and WASPAS Methods
}

\author{
Mohamed F. El-Santawy ${ }^{1}$,Soha Mohamed ${ }^{2}$ \\ ${ }^{1}$ Financial Researcher at Ministry of Finance, Egypt \\ (E-mail: lost_zola@yahoo.com) \\ ${ }^{2}$ Faculty of Graduate Studies for Statistical Research, Cairo University, Egypt \\ (E-mail: smm_elmasry@yahoo.com)
}

\begin{abstract}
The process of ranking alternatives in Multi-Criteria Decision Making (MCDM) problems with rough intervals is a situation really tough to handle. Despite, there are dozens of proposals to handle MCDM problems under different types of uncertainty but still there is limited number of articles to explore Rough MCDM specially, the rough interval ones with no weights for criteria. Mainly, this research is to propose a new approach combining two novel methods to treat such MCDM problems. First, Rough Interval Best-Worst Method (RIBWM), where RIBWM is applied for assigning weights to criteria based on the criteria preference given by the Decision Makers (DMs). This is done in a new manner to handle rough interval preference given. Second, a new Rough Interval Weighted Aggregated Sum-Product Assessment method (RIWASPAS) is presented to rank the alternatives. A merit of this new approach that it sustains rough interval representation of the problem till the end as well as it deals with it efficiently. Finally, an illustrative example is provided for validation.
\end{abstract}

Key words: Best Worst Method, Multi-criteria Decision Making (MCDM), Rough Interval, WASPAS.

\section{INTRODUCTION}

On daily basis most of people face situations involving criteria of judgment are not compatible. This type of decisions is so-called MCDM and it refers to undertaking decisions under the existence of conflicting criteria. For illustration if one criterion is fulfilled or satisfied by an option, there is other criterion is not satisfied or fulfilled with the same option. Both words multiple or multi which are coined to criteria refer to the conflict between not the meaning of many criteria. This philosophy makes this branch is widely applied [7]. A typical MCDM problem contains a number of competing alternatives measured via number of criteria [6]. Performance measurements should be done and calculated for all alternatives under all criteria considered [10]. Some of the most widely used MCDM methods are SAW, MAUT, AHP, PROMETHEE, COPRAS, and ELECTRE methods [4].

In MCDM, the weights reflect the comparative importance and play the biggest role in determining the best alternatives to be selected. Two main categories exist for allocating weights, Subjective and Objective weights' allocation methods. Subjective weights' allocation methods are translating the preference of Decision Maker(s) into quantified values while the Objective weights' allocation methods are extracting weights from the alternatives' performance measurements [5].

One of the critical criticisms of the AHP refers to its inconsistency of decision makers' judgments in pairwise comparisons [20]. Recently, the Best-Worst Method (BWM) was introduced to tackle such drawbacks [16]. BWM has been applied broadly like in [2], and [18].

In many real-life problems, different types of uncertainty are found. Guo and Zhang tackled the supplier selection problem [9]; Aydogan tried to rank aviation firms [1]. Radovic et. al. introduced a rough ARAS approach [14]. Many other applications are done like in [3] [8], [12], [15], and [19].

The WASPAS method adds in some manner the Weighted Sum Model (WSM) to the Weighted Product Model (WPM) with certain ratio derived from a coefficient to reach the highest accuracy of multiple attribute estimation [15]. This article is to propose a new approach for solving rough interval MCDM problems using the merits of a novel incorporation between a new Weighted Aggregated SumProduct Assessment Method with Rough Interval (RIWASPAS) and a novel Rough Interval Best-Worst Method (RIBWM). The rest of this paper is organized as following; section 2 is made for Rough Set Theory and it contains an illustration of Rough Interval operations. Section 
3 is made for the proposed approach; it shows the rough interval Best-Worst Method (RIBWM) weights allocation proposed scheme as well as the steps of the proposed approach (RIWASPAS). Section 4 is devoted to a numerical example for illustration; and finally section 5 is for conclusion.

\section{ROUGH SET THEORY}

The main idea behind rough set theory initially proposed by Pawlak is an approximation of a conventional set in terms of two sets the upper and lower approximations of the original set [13]. Generally, a rough interval contains two parts: an upper approximation interval (UAI) and a lower approximation interval (LAI) [12]

\section{Basic Operations of Rough Interval}

Let $* \in\{+,-, \times, \div\}$ be a binary operation on rough intervals. For rough intervals $x^{R}$ and $y^{R}$ when $x^{R} \geq 0$ and $\mathrm{y}^{\mathrm{R}} \geq 0$, we have [11]:

$$
\begin{aligned}
& x^{R}+y^{R}=\left[\left[x^{(\mathrm{UAI})}+y^{(\mathrm{UAI})}\right]:\left[x^{(\mathrm{LAI})}+y^{(\mathrm{LAI})}\right]\right] \\
& \mathrm{x}^{\mathrm{R}}-\mathrm{y}^{\mathrm{R}}=\left[\left[\mathrm{x}^{(\mathrm{UAI})}-\mathrm{y}^{(\mathrm{UAI})}\right]:\left[\mathrm{x}^{(\mathrm{LAI})}-\mathrm{y}^{(\mathrm{LAI})}\right]\right] \\
& \mathrm{x}^{\mathrm{R}} \times \mathrm{y}^{\mathrm{R}}=\left[\left[\mathrm{x}^{(\mathrm{UAI})} \times \mathrm{y}^{(\mathrm{UAI})}\right]:\left[\mathrm{x}^{(\mathrm{LAI})} \times \mathrm{y}^{(\mathrm{LAI})}\right]\right] \\
& \mathrm{x}^{\mathrm{R}} \div \mathrm{y}^{\mathrm{R}}=\left[\left[\mathrm{x}^{(\mathrm{UAI})} \div \mathrm{y}^{(\mathrm{UAI})}\right]:\left[\mathrm{x}^{(\mathrm{LAI})} \div \mathrm{y}^{(\mathrm{LAI})}\right]\right]
\end{aligned}
$$

As $\quad x^{(U A I)}, x^{(L A I)}, y^{(U A I)}$ and $y^{(L A I)}$ are conventional intervals, $\quad x^{U A I}=\left[x^{(-U A I)}, x^{(+U A I)}\right] \quad, \quad x^{L A I}=$ $\left[x^{(-L A I)}, x^{(+L A I)}\right], y^{U A I}=\left[y^{(-U A I)}, y^{(+U A I)}\right]$, and $y^{L A I}=$ $\left[y^{(-L A I)}, y^{(+L A I)}\right], \quad$ where $\quad x^{(-L A I)}, x^{(+L A I)}$ $y^{(-U A I)}, y^{(+U A I)}, y^{(-L A I)}$, and $y^{(+L A I)}$ are deterministic numbers denoting bounds of intervals.

\section{PROPOSED APPROACH}

In this section, the new Approach is introduced to solve (MCDM) problems under rough interval environment via tow novel methods. First subsection will illustrates the novel proposed weights' allocation method (RIBWM) which works under rough interval environment to produce rough weights and second subsection will shows the new proposed (RIWASPAS) which deals with rough intervals' alternatives and criteria.

\subsection{Rough Interval Best-Worst Method (RIBWM)}

The original BWM found in [17] relies on two steps, first identifying the best criterion and the worst criterion by the DM. After, The DM expresses how better the best and how worse is the worst relative to other criteria using the scale (e.g. 1 to 9). As shown it eliminates a lot of pairwise comparisons made by other subjective methods. This subsection extends the classical BWM method to the rough interval environment. The steps of the new Rough Interval Best-Worst Method (RIBWM) method to determine the rough interval weight of each criterion can be as shown below:

Step 1: Define the set of decision factors

DM introduces $n$ decision factors, namely $\left\{c_{1}, c_{2}, \ldots, c_{n},\right\}$ to make a decision.

Step 2: Specify the Best decision factor (B) and the Worst decision factor $(W)$

Step 3: Identify the preference of the rough interval best decision factor over the other decision factors

The rough interval best-to-others $(\mathrm{BO})$ vector is:

$A_{B}^{R I}=\left(a_{B 1}^{R I}, a_{B 2}^{R I}, \ldots, a_{B n}^{R I}\right)$

$\mathrm{a}_{\mathrm{BB}}^{\mathrm{RI}}=[1,1]:[1,1]$

$\mathrm{a}_{\mathrm{Bj}}^{\mathrm{RI}}$ represents the preference of the rough interval best factor $B$ over selection factor $j$.

Step 4: Identify the preference the rough interval of all decision factors over worst decision factor

The rough interval others-to-worst $(\mathrm{OW})$ vector is:

$$
\begin{aligned}
& \mathrm{A}_{\mathrm{w}}^{\mathrm{RI}}=\left(\mathrm{a}_{1 \mathrm{w}}^{\mathrm{RI}}, \mathrm{a}_{2 \mathrm{w}}^{\mathrm{RI}}, \ldots, \mathrm{a}_{\mathrm{nw}}^{\mathrm{RI}}\right)^{T} \\
& \left(\mathrm{a}_{\mathrm{ww}}^{\mathrm{RI}}\right)=[1,1]:[1,1]
\end{aligned}
$$

$a_{j w}^{R I}$ represents the preference of selection factor $j$ over the rough interval worst decision factor $W$.

Step 5: Compute the best possible rough interval weights

The rough weights' vector $\left(\mathrm{w}_{1}^{\mathrm{RI}}, \mathrm{w}_{2}^{\mathrm{RI}}, \ldots, \mathrm{w}_{\mathrm{n}}^{\mathrm{RI}}\right)$ is calculated by the Model as shown in Eq. [7]:

Min $\varepsilon$

S.t

$\left[\frac{\left[\mathrm{w}_{\mathrm{B}}^{-\mathrm{UAI}}, \mathrm{w}_{\mathrm{B}}^{+\mathrm{UAI}}\right]:\left[\mathrm{w}_{\mathrm{B}}^{-\mathrm{LAI}}, \mathrm{w}_{\mathrm{B}}^{+\mathrm{LAI}}\right]}{\left[\mathrm{w}_{j}^{-\mathrm{UAI}}, \mathrm{w}_{j}^{+\mathrm{UAI}}\right]:\left[\mathrm{w}_{j}^{-\mathrm{LAI}}, \mathrm{w}_{j}^{+\mathrm{LAI}}\right]}-\left[\mathrm{a}_{\mathrm{Bj}}^{-\mathrm{UAI}}, \mathrm{a}_{\mathrm{Bj}}^{+\mathrm{UAI}}\right]:\left[\mathrm{a}_{\mathrm{Bj}}^{-\mathrm{LAI}}, \mathrm{a}_{\mathrm{Bj}}^{+\mathrm{LAI}}\right]\right] \leq \varepsilon$ for all $j$

$\left[\frac{\left[\mathrm{w}_{j}^{-\mathrm{UAI}}, \mathrm{w}_{j}^{+\mathrm{UAI}}\right]:\left[\mathrm{w}_{j}^{-\mathrm{LAI}}, \mathrm{w}_{\mathrm{j}}^{+\mathrm{LAI}}\right]}{\left[\mathrm{w}_{\mathrm{w}}^{-\mathrm{WAI}}, \mathrm{w}_{\mathrm{w}}^{+\mathrm{UAI}}\right]:\left[\mathrm{w}_{\mathrm{w}}^{-\mathrm{LAI}}, \mathrm{w}_{\mathrm{w}}^{+\mathrm{LAI}}\right]}-\left[\mathrm{a}_{\mathrm{jw}}^{-\mathrm{UAI}}, \mathrm{a}_{\mathrm{jw}}^{+\mathrm{UAI}}\right]:\left[\mathrm{a}_{j \mathrm{w}}^{-\mathrm{LAI}}, \mathrm{a}_{\mathrm{jw}}^{+\mathrm{LAI}}\right]\right] \leq \varepsilon$ for all $j$

$\sum_{j=1}^{n}\left[\left[\mathrm{w}_{\mathrm{j}}^{-\mathrm{UAI}}, \mathrm{w}_{\mathrm{j}}^{+\mathrm{UAI}}\right]:\left[\mathrm{w}_{\mathrm{j}}^{-\mathrm{LAI}}, \mathrm{w}_{\mathrm{j}}^{+\mathrm{LAI}}\right]\right]=1$

$\left[\mathrm{w}_{j}^{-\mathrm{UAI}}, \mathrm{w}_{j}^{+\mathrm{UAI}}\right]:\left[\mathrm{w}_{j}^{-\mathrm{LAI}}, \mathrm{w}_{j}^{+\mathrm{LAI}}\right] \geq 0$

for all $j$

where $\left[w_{j}^{-U A I}, w_{j}^{+U A I}\right]:\left[w_{j}^{-L A I}, w_{j}^{+L A I}\right]$ are the rough interval weights' values. $\left[\mathrm{w}_{B}^{-\mathrm{UAI}}, \mathrm{w}_{B}^{+\mathrm{UAI}}\right]:\left[\mathrm{w}_{B}^{-\mathrm{LAI}}, \mathrm{w}_{\mathrm{B}}^{+\mathrm{LAI}}\right]$ represents 
the rough interval weights of the best criterion and $\left[\mathrm{w}_{\mathrm{w}}^{-\mathrm{UAI}}, \mathrm{w}_{\mathrm{w}}^{+\mathrm{UAI}}\right]:\left[\mathrm{w}_{\mathrm{w}}^{-\mathrm{LAI}}, \mathrm{w}_{\mathrm{w}}^{+\mathrm{LAI}}\right]$ the rough interval weights of the worst criterion. While $\left[\mathrm{a}_{\mathrm{Bj}}^{-\mathrm{UAI}}, \mathrm{a}_{\mathrm{Bj}}^{+\mathrm{UAI}}\right]:\left[\mathrm{a}_{\mathrm{Bj}}^{-\mathrm{LAI}}, \mathrm{a}_{\mathrm{Bj}}^{+\mathrm{LAI}}\right]$ and $\left[a_{j w}^{-\mathrm{UAI}}, \mathrm{a}_{\mathrm{jw}}^{+\mathrm{UAI}}\right]:\left[\mathrm{a}_{\mathrm{jw}}^{-\mathrm{LAI}}, \mathrm{a}_{\mathrm{jw}}^{+\mathrm{LAI}}\right], \quad$ respectively represent the values of the rough interval best-to-others (BO) and the rough interval others-to-worst (OW). By solving model (7) we obtain the values of the rough interval weights for the evaluation criteria.

\subsection{Rough Interval Weighted Aggregated Sum-Product Assessment method (RIWASPAS)}

Some modifications should be done to WASPAS method in order to explore the rough interval environment [21]. In this subsection these modifications are illustrated to extend WASPAS method to deal with problems when the data given are rough intervals. The proposed RIWASPAS method consists of the following steps:

Step 1: Construct the decision matrix with RI $X^{R I}$

$X^{R I}=\left[\begin{array}{ccccc}x_{11}^{R I} & \cdots & x_{12}^{R I} \cdots & x_{1 n}^{R I} \\ \vdots & & \ddots & & \vdots \\ x_{21}^{R I} & \cdots & x_{22}^{R I} & \cdots & x_{2 n}^{R I} \\ \vdots & & \ddots & & \vdots \\ x_{m 1}^{R I} & \cdots & x_{m 2}^{R I} & \cdots & x_{m n}^{R I}\end{array}\right]$

$i=1,2, \ldots, m ; j=1,2, \ldots, n$

where $x_{i j}^{R I}=\left[x_{i j}^{L A I}, x_{i j}^{U A I}\right], x_{i j}^{L A I}=\left[x_{i j}^{-L A I}, x_{i j}^{+L A I}\right], x_{i j}^{-L A I}=$ lower lower interval and $x_{i j}^{+L A I}=$ lower upper interval. $\mathrm{x}_{\mathrm{ij}}^{\mathrm{UAI}}=$ $\left[\mathrm{x}_{\mathrm{ij}}^{-\mathrm{UAI}}, \mathrm{x}_{\mathrm{ij}}^{+\mathrm{UAI}}\right], \mathrm{x}_{\mathrm{ij}}^{-\mathrm{UAI}}=$ upper lower interval and $\mathrm{x}_{\mathrm{ij}}^{+\mathrm{UAI}}=$ upper upper interval, $m=$ number of alternatives, $\mathrm{n}=$ number of criteria, $i=1,2, \ldots, m$; and $j=1,2, \ldots, n$.

Step 2: Normalize the RI decision-making matrix

For rough interval beneficial criteria

$\bar{x}_{i j}^{R I}=\frac{\left[\left[x_{i j}^{-U A I}, x_{i j}^{+U A I}\right]:\left[x_{i j}^{-L A I}, x_{i j}^{+L A I}\right]\right]}{\max \left[x_{i j}^{+U A I}, x_{i j}^{+L A I}\right]}$

For rough interval non-beneficial criteria

$\bar{x}_{i j}^{R I}=\frac{\min \left[x_{i j}^{-U A I}, x_{i j}^{-L A I}\right]}{\left.\left[x_{i j}^{-U A I}, x_{i j}^{+U A I}\right]:\left[x_{i j}^{-L A I}, x_{i j}^{+L A I}\right]\right]}$

Where $\bar{x}_{i j}^{R I}$ is the normalized value of $x_{i j}^{R I}$.

Step 3: Calculate the weighted normalized RI decision matrix $\hat{X}^{R I}$

a. The weighted normalized RI decision matrix $\hat{X}_{q}^{R I}$ for WSM:

$$
\begin{aligned}
& \hat{x}_{i j}^{R I}=\left[\left[\bar{x}_{i j}^{-U A I}, \bar{x}_{i j}^{+U A I}\right]:\left[\bar{x}_{i j}^{-L A I}, \bar{x}_{i j}^{+L A I}\right]\right] \times \mathrm{W}_{\mathrm{j}}^{\mathrm{RI}} \\
& i=1,2, \ldots, m ; j=0,1,2, \ldots, n
\end{aligned}
$$

where $\mathrm{W}_{\mathrm{j}}^{\mathrm{RI}}$ is the $\mathrm{RI}$ weight(importance) ofthe $j$ criterion and $\hat{x}_{i j}^{R I}$ is the rough interval normalized rating of the $j$ criterion.

b. The weighted normalized RI decision matrix $\hat{X}_{p}^{R I}$ for WPM:

$$
\begin{gathered}
\hat{\bar{x}}_{i j}^{R I}=\left[\left[\bar{x}_{i j}^{-U A I}, \bar{x}_{i j}^{+U A I}\right]:\left[\bar{x}_{i j}^{-L A I}, \bar{x}_{i j}^{+L A I}\right]\right]^{\mathrm{W}_{\mathrm{j}}^{\mathrm{RI}}} \\
i=1,2, \ldots, m ; j=0,1,2, \ldots, n
\end{gathered}
$$

\section{Step 4: Calculate values of the optimality function}

a. according to the RI WSM for each alternative:

$$
\begin{aligned}
\hat{x}_{i j}^{R I} & =\left[\left[\bar{x}_{i j}^{-U A I}, \bar{x}_{i j}^{+U A I}\right]:\left[\bar{x}_{i j}^{-L A I}, \bar{x}_{i j}^{+L A I}\right]\right] \\
Q_{i}^{R I} & =\sum_{j=1}^{n} \hat{x}_{i j}^{R I}, i=1,2, \ldots, m
\end{aligned}
$$

b. according to the RI WPM for each alternative:

$$
\begin{aligned}
& \hat{\bar{x}}_{i j}^{R I}=\left[\left[\bar{x}_{i j}^{-U A I}, \bar{x}_{i j}^{+U A I}\right]:\left[\bar{x}_{i j}^{-L A I}, \bar{x}_{i j}^{+L A I}\right]\right]^{\mathrm{W}_{\mathrm{j}}^{\mathrm{RI}}} \\
& P_{i}^{R I}=\prod_{j=1}^{n} \hat{\bar{x}}_{i j}^{R I}, \quad i=1,2, \ldots, m
\end{aligned}
$$

Step 5: Calculate the integrated utility function value of the RIWASPAS

For an alternative $(i)$ the integrated utility function could be determined as follows:

$K_{i}^{R I}=\left[K_{i}^{-U A I}, K_{i}^{+U A I}, K_{i}^{-L A I}, K_{i}^{+L A I}\right]$

$K_{i}^{R I}=\lambda \sum_{j=1}^{n} Q_{i}^{R I}+(1-\lambda) \prod_{j=1}^{n} P_{i}^{R I}$

Coefficient $(\lambda)$ can be crisp values in the range of $[0,1]$ but it is recommended to apply Eq.(16) for its calculation

$$
\lambda=\frac{\sum_{i=1}^{m} P_{i}^{R I}}{\sum_{i=1}^{m} Q_{i}^{R I}+\sum_{i=1}^{m} P_{i}^{R I}}
$$

Step 6: Transform the RI values of $K_{i}^{R I}$ into crisp values by the centroid method

$K_{i}=\frac{1}{4}\left[K_{i}^{-U A I}+K_{i}^{+U A I}+K_{i}^{-L A I}+K_{i}^{+L A I}\right]$

Step 7: Rank the alternatives, the best of them with maximum $K_{i}$ value

\section{NUMERICAL EXAMPLE}

As shown below the numerical example is composed from five competing alternatives $\left(\mathrm{A}_{1}, \mathrm{~A}_{2}, \mathrm{~A}_{3}, \mathrm{~A}_{4}, \mathrm{~A}_{5}\right)$ and four criteria. $C_{2}, C_{3}$ and $C_{4}$ are the beneficial while $C_{1}$ is cost or non-beneficial type. The RI decision matrix presented in Table 1 is defined as in Eq. (8). Results and illustration are shown later in the rest of the section. 
Table 1: Rough interval decision making matrix

\begin{tabular}{|c|c|c|c|c|}
\hline & & Criteria & & \\
\hline Optimization & Min & Max & Max & Max \\
\hline \multirow{2}{*}{ Alternatives } & $\mathrm{C}_{1}$ & $\mathrm{C}_{2}$ & $\mathrm{C}_{3}$ & $\mathrm{C}_{4}$ \\
\hline & LAI & UAI & LAI & LAI \\
\hline$A_{1}$ & {$[[200,250]:[220,240]]$} & {$[[585,620]:[600,610]]$} & {$[[690,720]:[710,715]]$} & {$[[790,810]:[795,800]]$} \\
\hline$A_{2}$ & {$[[300,360]:[330,340]]$} & {$[[625,640]:[630,635]]$} & {$[[730,760]:[740,750]]$} & {$[[820,850]:[830,840]]$} \\
\hline$A_{3}$ & {$[[400,450]:[430,445]]$} & {$[[300,500]:[450,480]]$} & {$[[770,785]:[775,780]]$} & {$[[790,860]:[835,845]]$} \\
\hline$A_{4}$ & {$[[500,540]:[520,530]]$} & {$[[650,680:[655,670]]$} & {$[[600,700]:[650,680]]$} & {$[[865,885]:[870,880]]$} \\
\hline$A_{5}$ & [[550,580]:[560,570]] & {$[[500,690]:[590,680]]$} & {$[[775,790]:[780,785]]$} & {$[[785,895]:[850,890]]$} \\
\hline
\end{tabular}

\section{Results and Discussion}

First, RIBWM method is applied to determine the weights of criteria. In this problem, $\mathrm{C}_{2}$ and $\mathrm{C}_{4}$ are selected as the best and the worst criteria, respectively. The rough interval Preferences of the best criterion over the less important
Criteria and other criteria over the worst criterion should be determined by integers as found in Tables 2 and 3, respectively. Weights are assigned to criteria by solving the Mathematical Model found in Eq. (7). Then, the final overall weights will be as shown in Table 4 .

Table 2: Rough interval best-to-others (BO) vector

\begin{tabular}{ccccc}
\hline Criteria & $\mathbf{C}_{\mathbf{1}}$ & $\mathbf{C}_{\mathbf{2}}$ & $\mathbf{C}_{\mathbf{3}}$ & $\mathbf{C}_{\mathbf{4}}$ \\
& UAI $:$ LAI & UAI $:$ LAI & UAI $:$ LAI & UAI : LAI \\
\hline Best Criterion: $\mathbf{C}_{2}$ & {$[3,8]:[5,5]$} & {$[1,1]:[1,1]$} & {$[5,7]:[3,6]$} & {$[6,5]:[9,8]$} \\
\hline
\end{tabular}

Table 3: Rough interval others-to-worst (OW) vector

\begin{tabular}{ccccc}
\hline Criteria & $\mathbf{C}_{\mathbf{1}}$ & $\mathbf{C}_{\mathbf{2}}$ & $\mathbf{C}_{\mathbf{3}}$ & $\mathbf{C}_{4}$ \\
& UAI $:$ LAI & UAI $:$ LAI & UAI $:$ LAI & UAI : LAI \\
\hline Worst criterion: $\mathbf{C}_{4}$ & {$[2,6]:[5,6]$} & {$[6,5]:[9,8]$} & {$[4,4]:[5,7]$} & {$[1,1]:[1,1]$} \\
\hline
\end{tabular}

Table 4: Weights allocated using RIBWM method

\begin{tabular}{cc}
\hline Criteria & $\boldsymbol{W}_{j}^{R I}$ \\
\hline $\mathbf{C}_{\mathbf{1}}$ & {$[0.121926,0.232558]:[0.139024,0.170984]$} \\
$\mathbf{C}_{\mathbf{2}}$ & {$[0.55814,0.667009]:[0.578049,0.634715]$} \\
$\mathbf{C}_{\mathbf{3}}$ & $[0.139344,0.231707]:]:[0.139535,0.142487]$ \\
$\mathbf{C}_{\mathbf{4}}$ & {$[0.05122,0.071721]:[0.051813,0.069767]$} \\
\hline
\end{tabular}

Second, by applying the procedure of RIWASPAS method, we obtain the solution results for rough interval WSM and rough interval WPM for each alternative as in table 5 by applying Eqs. (9-14). Table 6 shows the Integrated utility function values of the RIWASPAS method by using Eqs. (15-16). After which, the Final rank of alternatives based on Eq. (17) as shown in Table 7.

Table 5: Solution results for rough interval WSM and rough interval WPM

\begin{tabular}{ccc}
\hline Alternatives & $\boldsymbol{Q}_{\boldsymbol{i}}^{\boldsymbol{R} \boldsymbol{I}}$ & $\boldsymbol{P}_{\boldsymbol{i}}^{\boldsymbol{R} \boldsymbol{I}}$ \\
\hline $\mathbf{A}_{\mathbf{1}}$ & {$[0.737663,1.107986]:[0.809968,0.932855]$} & {$[0.865372,0.914207]:[0.900948,0.904831]$} \\
$\mathbf{A}_{\mathbf{2}}$ & {$[0.748987,1.064737]:[0.805359,0.908684]$} & {$[0.854585,0.890012]:[0.867293,0.883982]$} \\
$\mathbf{A}_{\mathbf{3}}$ & {$[0.477886,0.898776]:[0.637632,0.743334]$} & {$[0.563427,0.711633]:[0.683614,0.71058]$} \\
$\mathbf{A}_{\mathbf{4}}$ & {$[0.726275,1.026596]:[0.780693,0.890132]$} & {$[0.777509,0.842485]:[0.823233,0.837166]$} \\
$\mathbf{A}_{\mathbf{5}}$ & {$[0.628116,1.055004]:[0.743332,0.914142]$} & {$[0.726896,0.852355]:[0.790368,0.804373]$} \\
\hline
\end{tabular}


Table 6: Integrated utility function values of the RIWASPAS method

$$
\lambda=[0.404514,0.592495]:[0.476603,0.528016]
$$

\begin{tabular}{rccc} 
Alt. & $\boldsymbol{\lambda} \times \boldsymbol{Q}_{\boldsymbol{i}}^{\boldsymbol{R I}}$ & \multicolumn{1}{c}{$(\mathbf{1}-\boldsymbol{\lambda}) \times \boldsymbol{P}_{\boldsymbol{i}}^{\boldsymbol{R I}}$} & \multicolumn{1}{c}{$\boldsymbol{K}_{\boldsymbol{i}}^{\boldsymbol{R} \boldsymbol{I}}$} \\
\hline $\mathbf{A}_{\mathbf{1}}$ & {$[0.298395,0.656476]:[0.386033,0.492562]$} & {$[0.352644,0.544397]:[0.425233,0.473587]$} & {$[0.651039,1.200873]:[0.811266,0.966148]$} \\
$\mathbf{A}_{\mathbf{2}}$ & {$[0.302976,0.630851]:[0.383836,0.479799]$} & {$[0.348248,0.529989]:[0.409349,0.462674]$} & {$[0.651224,1.16084]:[0.793185,0.942473]$} \\
$\mathbf{A}_{\mathbf{3}}$ & {$[0.193312,0.53252]:[0.303897,0.392492]$} & {$[0.229599,0.423767]:[0.322655,0.371916]$} & {$[0.422911,0.956288]:[0.626552,0.764408]$} \\
$\mathbf{A}_{\mathbf{4}}$ & {$[0.293789,0.608253]:[0.37208,0.470004]$} & {$[0.316839,0.501688]:[0.388553,0.438171]$} & {$[0.610628,1.109941]:[0.760633,0.908175]$} \\
$\mathbf{A}_{\mathbf{5}}$ & {$[0.254082,0.625085]:[0.354274,0.482681]$} & {$[0.296214,0.507565]:[0.373041,0.421007]$} & {$[0.550296,1.13265]:[0.727315,0.903688]$} \\
\hline
\end{tabular}

Table 7: Final rank of alternatives

\begin{tabular}{lcc}
\hline & $\boldsymbol{K}_{\boldsymbol{i}}$ & Rank \\
\hline $\mathbf{A}_{\mathbf{1}}$ & 0.907332 & $\mathbf{1}$ \\
$\mathbf{A}_{\mathbf{2}}$ & 0.88693 & 2 \\
$\mathbf{A}_{\mathbf{3}}$ & 0.69254 & 5 \\
$\mathbf{A}_{\mathbf{4}}$ & 0.847344 & 3 \\
$\mathbf{A}_{\mathbf{5}}$ & 0.828487 & 4 \\
\hline
\end{tabular}

Then, the final rank of alternatives by applying the new RIWASPAS method is as follows: $A_{1}>A_{2}>A_{4}>A_{5}>A_{3}$. The highest value represents the best alternative, which in this case is alternative $A_{1}$, while the worst one is alternative $A_{3}$.

\section{CONCLUSION}

This paper proposed a novel combination rough interval MCDM approach for selecting a suitable alternative under rough interval. RIBWM and RIWASPAS are two novel methods employed together in the proposed method; the RIBWM was used to determine the weights of the attributes, while RIWASPAS was employed to rank the alternative. The proposed method is practical and efficient in rough interval domain. An illustrative example is given to show the results for testing the proposed approach.

\section{REFERENCES}

1. E. K. Aydogan. Performance measurement model for Turkish aviation firms using the rough-AHP and TOPSIS methods under fuzzy environment, Expert Syst. Appl., 38(4), pp. 3992-3998, 2011.

2. N. Chitsaz and A. Azarivand. Water Scarcity Management in Arid Regions Based on an Extended Multiple Criteria Technique, Water Resour. Manag, 3, pp. 233-250, 2016. https://doi.org/10.1007/s11269-016-1521-5

3. S. Chakraborty and E. K. Zavadskas. Applications of WASPAS Method in Manufacturing Decision Making, Informatica, 25(1), pp: 1-20, 2014.

4. P. Chatterjee and S. Chakraborty. Material selection using preferential ranking methods, Materials and Design, 35, pp. 384-393, 2012.

5. M. F. El-Santawy. A CV-COPRAS Approach for Solving Multi-Criteria Decision Making Problems, Computing and Information Systems Journal, 19(2), pp.15-18, 2015.

6. M. F. El-Santawy. A VIKOR Method for Solving Personnel Training Selection Problem, International Journal of Computing Science, ResearchPub, 1(2), pp. 9-12, 2012.

7. M. F. El-Santawy and A. N. Ahmed. A VIKOR Approach for Project Selection Problem, $L I F E$ SCIENCE JOURNAL-ACTA ZHENGZHOU UNIVERSITY OVERSEAS EDITION, 9(4), pp. 58785880, 2012.

8. L. Gigovic, D. Pamucar, Z. Bajic and S. Drobnjak. Application of GIS-Interval Rough AHP Methodology for Flood Hazard Mapping in Urban Areas, Water, 9(6), pp. 1-26, 2017. https://doi.org/10.3390/w9060360

9. J. Guo and W. Zhang. Selection of Suppliers Based on Rough Set Theory and VIKOR Algorithm, International Symposium on Intelligent Information Technology Application Workshops, IEEE, pp. 49-52, 2008.

10. P. Karandea, E. K. Zavadskas and S. Chakrabortyc. A study on the ranking performance of some MCDM methods for industrial robot selection problems, International Journal of Industrial Engineering Computations, 7, pp. 399 - 422, 2016.

11. H. Lu, G. Huang and L. He. An inexact roughinterval fuzzy linear programming method for generating conjunctive water-allocation strategies to agricultural irrigation systems, Applied Mathematical Modelling, 35, pp. 4330-4340, 2011.

12. D. Pamucar and G. Cirovic. The selection of transport and handling resources in logistics centers using Multi-Attributive Border Approximation Area Comparison (MABAC), 
Expert Systems with Applications, 42(6), pp. 30163028, 2015.

13. Z. Pawlak. Rough sets, International Journal of Computer and Information Science, 11(5), pp. 341342, 1982.

14. D. Radovic, Z. Stevic, D. Pamucar , E. K. Zavadskas, I. Badi, J. Antucheviciene and Z. Turskis. Measuring Performance in Transportation Companies in Developing Countries: ANovel Rough ARAS Model, Symmetry, 10(434), pp. 1-24, 2018. https://doi.org/10.3390/sym10100434

15. J. Roy, K. Chatterjee, A. Bandhopadhyay and S. Kar. Evaluation and selection of Medical Tourism sites: A rough AHP based MABAC approach, doi: arXiv : 1606.08962, 2016.

16. J. Rezaei. Best-worst multi-criteria decisionmaking method: Some properties and a linear model, Omega, 64, pp. 126-130, 2016.

17. J. Rezaei. Best-worst multi-criteria decisionmaking method, Omega, 53, pp. 49-57, 2015.

18. J. Rezaei, J. Wang and L. Tavasszy. Linking supplier development to supplier segmentation using Best Worst Method, Expert Syst. Appl., 42, pp. 9152-9164, 2015.

19. M. Rebolledo. Rough intervals-enhancing intervals for qualitative modeling of technical systems, Artificial Intelligence, 170, pp. 667-685, 2006. https://doi.org/10.1016/j.artint.2006.02.004

20. T. Saaty. The analytic hierarchy process, McGrawHill, New York, 1980.

21. E. K. Zavadskas, Z. Turskis, J. Antucheviciene and A. Zakarevicius. Optimization of Weighted Aggregated Sum Product Assessment, Electronics and Electrical Engineering = Elektronika Ir Elekhotechnika, 122(6), pp. 3-6, 2012. https://doi.org/10.5755/j01.eee.122.6.1810 